\title{
Programa de educação nutricional em escola de ensino fundamental de zona rural ${ }^{1}$
}

\author{
Nutrition education program in \\ a rural elementary school
}

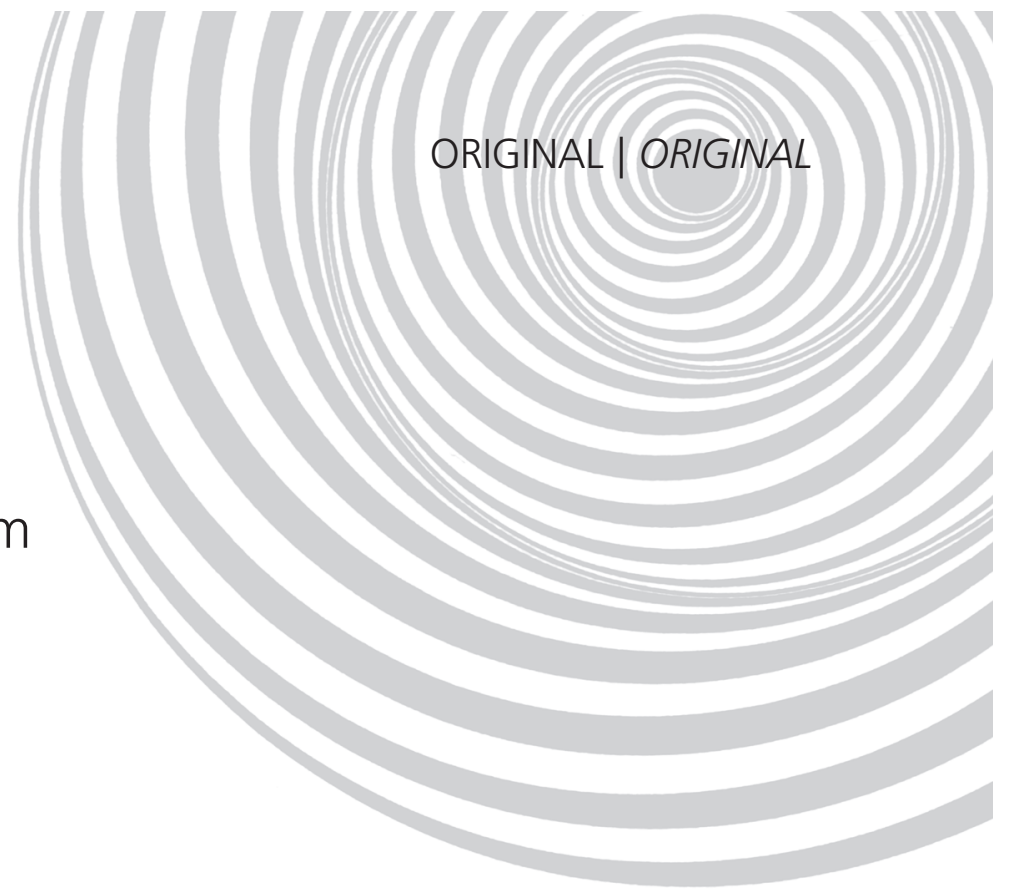

Maria Cristina Faber BOOG²

RE S U M O

\section{Objetivo}

Apresentar métodos e tecnologias de intervenção em educação alimentar e nutricional, criados com base em diagnóstico realizado no âmbito de escola e comunidade, tendo como pressuposto teórico a relação homem/ ambiente, mediada pelo trabalho.

\section{Métodos}

A abordagem foi pautada nos conceitos de promoção da saúde, nutrição comunitária e educação problematizadora. O programa, denominado "Ensinando a amar a terra e o que a terra produz" foi desenvolvido com 155 alunos de pré-escola a $7^{a}$ série, em uma unidade de ensino de zona rural do Estado de São Paulo, Brasil. Constou de: apresentação dos resultados do diagnóstico para professores e famílias de alunos; produção de história contendo elementos do diagnóstico; confecção de maquete; degustação de fruta da produção regional; exposição da maquete para as famílias.

\section{Resultados}

A metodologia e tecnologias empregadas despertaram interesse pelas atividades porque estas refletiam o cotidiano e valorizavam o trabalho, a história, a identidade cultural, fortalecendo a autoestima das famílias. A fruta foi ressignificada enquanto direito do agricultor que a produz. Foram observados conflitos de interesse entre prefeitura e executores do programa.

\section{Conclusão}

Foi possível criar um programa de educação alimentar e nutricional a partir da relação homem/ambiente, mediada pelo trabalho, na qual o tema alimentação teve como ponto de partida não a ciência da nutrição, mas um diagnóstico de práticas de consumo, valores, representações que subsidiaram a criação das tecnologias de intervenção. Conflitos de interesse descritos devem ser considerados ao se planejar políticas públicas de segurança alimentar e nutricional.

Termos de indexação: Educação alimentar e nutricional. Educação em saúde. Ensino fundamental e médio. Tecnologia educacional.

1 Apoio: Conselho Nacional de Desenvolvimento Científico e Tecnológico (Processo 402078/2005-5).

2 Universidade Estadual de Campinas, Núcleo de Estudos e Pesquisas em Alimentação. R. Albert Einstein, 291, 13083-852,

Campinas, SP, Brasil. E-mails: <crisboog@fcm.unicamp.br>; <cristinaboog@hotmail.com>. 
1006 | M.C.F. BOOG

\section{A B S T R A C T}

\section{Objective}

The present article presents methods and technologies for food and nutrition education interventions whose development was based on a diagnosis made at a school and community. The theoretical assumption was the work-mediated man-environment interaction.

\section{Methods}

The approach was guided by the concepts of health promotion, community nutrition and problem-solving education. The program, called "Teaching to love the land and what the land produces" was developed together with 155 students from preschool to seventh grade from a rural elementary school in the state of São Paulo, southeastern Brazil. The nutrition education program consisted of: presentation of the diagnosis to the teachers and students' families; development of a story based on diagnostic elements; construction of a scale model of the area; tasting of fruits cultivated locally; and exhibition of the scale-model to the families.

\section{Results}

The methods and technologies used awakened interest in the activities because they reflected their daily routines and valued their work, history and cultural identity, strengthening the families' self-esteem. Fruits received a new meaning, being a right of the producer. There were also conflicts of interest between the city hall and the researchers.

\section{Conclusion}

It was possible to create a food and nutrition program based on the work-mediated man/environment relationship, where the theme diet was not based on nutrition science, but on a diagnosis of the consumption practices, values and representations that promote the development of interventional technologies. The above mentioned conflicts of interest must be borne in mind when public policies on food and nutrition security are planned.

Indexing terms: Food and nutrition education. Health education. Education, primary and secondary. Educational technology.

\section{N T R O D U Ç Ã O}

O presente artigo refere-se ao relato de uma prática pedagógica em educação alimentar e nutricional, no qual se buscou tratar o tema alimentação a partir da relação homem/ambiente, mediada pelo trabalho. Esta intervenção constituiu a última etapa da pesquisa "Promoção da saúde, segurança alimentar nutrição: a contribuição da educação nutricional", a qual teve, por objetivo geral, desenvolver um programa de promoção da alimentação saudável, que fosse concebido a partir de um diagnóstico de consumo de alimentos e de fatores sócio-culturais relativos à alimentação. Entre outras justificativas que embasaram esse programa, foi destacada a necessidade de desenvolver tecnologia de educação para a promoção da alimentação saudável no contexto da zona rural, enfrentando o fato paradoxal constatado por vários estudos, de que é justamente nestas áreas que se encontra o mais baixo consumo de frutas, verduras e legumes ${ }^{1,2}$. O termo tecnologia refere-se ao estudo sobre como aplicar pragmaticamente os conhecimentos gerados pelas pesquisas científicas, em benefício da sociedade.

A concepção inicial do projeto "Promoção da saúde, segurança alimentar e nutrição: a contribuição da educação nutricional" teve como pressuposto o fato de que a educação alimentar e nutricional é uma das diretrizes da Política Nacional de Alimentação e Nutrição³, com vistas à promoção da alimentação saudável e concretização de um estado de segurança alimentar e nutricional para a população. Além disso, os Parâmetros Curriculares Nacionais preconizam que temas de relevância social, entre eles a saúde e, dentro dela, a alimentação, sejam tratados transversalmente no ensino fundamental ${ }^{4}$. 
Uma condição para a construção de programas de promoção da alimentação saudável, viáveis e eficazes, é que eles sejam pautados sobre diagnósticos que lancem luzes não só sobre o consumo alimentar, mas sobre a cultura e as condições de vida dos grupos humanos, de forma tal que eles possam ser planejados considerando necessidades e valores da comunidade.

Entre os espaços viáveis para o desenvolvimento de ações de educação nutricional voltadas à construção da segurança alimentar e nutricional, destaca-se a escola, que é um espaço estratégico de vivência e de formação de hábitos, onde os indivíduos passam parte importante de seu tempo ${ }^{5}$.

As ações de natureza interdisciplinar, como as que envolvem saúde e escola acontecem em áreas limítrofes entre diferentes setores de aplicação do conhecimento, exigindo criatividade e disposição para enfrentar o desafio de superar as cisões que historicamente fizeram com que os conhecimentos fossem apreendidos de forma compartimentada e as ações se dessem também com um mínimo de troca entre setores. A afirmação de Garcia ${ }^{6}$ contribui para esclarecer a natureza dessa dificuldade, quando aponta dois aspectos que, para ele, resumem a disjunção entre essas áreas:

1. É extremamente difícil a aceitação pelo pessoal ligado à pedagogia, a inclusão de um tema como alimentação de maneira articulada, tratando-o como algo vital para a saúde e segurança de nossas crianças. O mesmo vale para as temáticas ligadas aos demais temas cidadãos. 2. Há uma grande dificuldade do pessoal especializado da área de nutrição-alimentação para produzirem material didático apto a ser utilizado em cursos de formação de professores. Ao defenderem as próprias trincheiras produzem alentados calhamaços, com ênfase em nutrição, desprezando muitas vezes a abordagem cultural da alimentação. Isso impede o aproveitamento adequado desses textos pelos formadores de professores (p.40).
É importante considerar que o conhecimento especializado é uma abstração, ou seja, uma forma de extrair um objeto de seu contexto e de seu conjunto para introduzi-lo no setor específico da disciplina compartimentada ${ }^{7}$, no qual apenas os iniciados naquela ciência navegam com segurança. A disjunção no campo epistemológico está na raiz da dificuldade para concatenar as ações de diferentes setores e profissões para responder ao desafio da intersetorialidade, que é um princípio fundamental da Segurança Alimentar e Nutricional ${ }^{\text {. }}$.

O programa foi desenvolvido junto a uma escola rural de um município do Estado de São Paulo, pertencente ao denominado "Circuito das Frutas", localizada em um bairro constituído por sítios, onde vivem agricultores que trabalham na produção de frutas, geralmente em regime de meação.

A estreita relação entre o ambiente escolar e o local de trabalho das famílias dos escolares na região de produção de frutas oferecia oportunidade singular para resgatar e valorizar o que as famílias já haviam construído - a sua própria história, e ajudar as crianças a compreender o valor e a dignidade do trabalho de suas famílias na produção de alimentos.

Os primeiros contatos foram efetuados com as autoridades municipais que se mostraram receptivas ao programa, porém bastante céticas em relação ao consumo de frutas, pois, no seu entendimento, devido ao fato das famílias estarem continuamente em contato com a sua produção, este alimento não seria atrativo para elas.

O programa educativo foi criado com base em três pesquisas, que, juntas, constituíram o diagnóstico inicial. A súmula dos resultados das pesquisas que fizeram parte do projeto "Promoção da saúde, segurança alimentar e nutrição: a contribuição da educação nutricional" é apresentada a seguir, porque são esses resultados que nortearam e que dão sentido ao programa, cuja apresentação constitui o objeto do presente artigo. 


\section{Súmula do diagnóstico prévio ao programa}

Três pesquisas diagnósticas realizadas na escola e no bairro, situado em um Município do Circuito das Frutas, no Estado de São Paulo, nortearam o delineamento das ações que compuseram o programa educativo. Com a finalidade de olhar o fato alimentar ${ }^{9}$ de vários ângulos, nesse diagnóstico prévio foram combinados diferentes métodos e técnicas, o que pode ser considerado triangulação de métodos $^{10}$.

O primeiro estudo teve por objetivo específico avaliar o consumo de Frutas, Verduras e Legumes (FVL) pelas famílias de fruticultores, relacionando-a com trabalho, disponibilidade local desses produtos e produção para autoconsumo, ou seja, produção para consumo pela própria família e agregados ${ }^{11}$. O segundo consistiu em um estudo qualitativo, realizado com uma subamostra do anterior, empregando a técnica de entrevista não estruturada, focalizada. Esta teve como propósito estudar representações sociais sobre alimentação, entendendo que estas estão na raiz do comportamento alimentar e consequentemente da condição de saúde da população, ao mesmo tempo em que são construídas a partir das condições de vida e de trabalho da comunidade $^{12}$. O terceiro foi desenvolvido na escola frequentada pelos filhos dos agricultores. Também foi um estudo qualitativo, empregando a mesma técnica de entrevista, que teve por objetivo identificar e analisar práticas, normas, opiniões, atitudes e representações relacionadas à alimentação/ alimentação escolar, junto aos professores e funcionários da escola13.

Na pesquisa de campo, conseguiu-se acesso a $78,7 \%$ das famílias de alunos matriculados na escola, sendo que a maioria delas era de agricultores. Há agricultores assalariados, mas o sistema de produção é, em geral, a meação ou parceria, sistema que se desenvolveu em áreas onde antes existiam fazendas. O proprietário do terreno fornece o espaço para o plantio, ficando com direito sobre parte dos produtos produzidos. A situação vivida pelas famílias corresponde ao que Cândido ${ }^{14}$ observou sobre este sistema em outro Município do interior paulista: teoricamente, deveria haver um contrato escrito de parceria, entretanto, na maior parte das vezes, este não é lavrado. Na prática, não há garantias legais para o parceiro, embora existam de fato para o proprietário. As famílias de meeiros são constituídas, em geral, por seis a sete pessoas e a Renda Média Familiar Per capita (RMFPC) dos agricultores era de $R \$ 169,00$ (U\$79,66), menos de meio salário-mínimo vigente na época (2006). A renda pela venda das frutas só é obtida ao final do período de cultivo, geralmente um ano. O recurso que as famílias utilizam para as despesas do mês é uma quantia referida como "adiantamento". No cálculo da renda familiar mensal per capita não se considerou o ganho no final do ano agrícola. Os entrevistados relataram que, nesse acerto de contas, são feitos descontos referentes aos adiantamentos e outras despesas com a produção, de forma que às vezes o parceiro recebe, outras não recebe nada, e às vezes é informado de que ficou devendo. Quando fazem o acerto de contas, as famílias adquirem bens duráveis, representativos da recompensa concreta e duradoura pelo trabalho realizado. É importante ressaltar que esse rendimento não influencia o consumo médio de alimentos, uma vez que a manutenção da família se dá por intermédio dos adiantamentos, que têm um valor fixo e baixo, semelhante para todas as famílias que trabalham no regime de meação.

O consumo alimentar é muito semelhante entre as famílias. A renda mais elevada relaciona-se a um consumo maior de carne e de refrigerante. Do total de famílias entrevistadas, 70,5\% possuíam horta e 80,0\% algumas árvores frutíferas ao redor do domicílio.

No desjejum, 38,0\% consumiam apenas café, que geralmente era preparado pelo homem, marcando o início do dia de trabalho. Apenas $16,5 \%$ referiram beber café com leite, acompanhado por pão ou similar. A maioria dos almoços e jantares não contém verduras ou legumes, embora ao serem perguntados se consomem tais 
alimentos, 85\% responderam afirmativamente em relação a verduras e $83 \%$ a legumes, considerando-os integrantes de sua alimentação. No dia em que foi realizado o recordatório alimentar, $59,5 \%$ não consumiram frutas, $70,9 \%$ não consumiram verduras e $53,2 \%$ nenhum legume; $40,5 \%$ referiram ter comido alguma fruta, incluindo suco natural, $12,6 \%$ consumiram banana e 5,0\% goiaba; $10,1 \%$ beberam algum suco natural, $29,0 \%$ comeram alguma verdura e $46,8 \%$ algum legume, sendo tomate o mais frequente, apesar deste ser comprado pela maioria das famílias, pois apenas 4,0\% plantam tomate para autoconsumo. Esses resultados sugerem que o acesso à terra não é um fator que por si só favoreça a alimentação, porque as mulheres dispõe de pouco tempo para preparar as refeições da família, visto que também trabalham na lavoura.

Verduras e legumes são considerados alimentos secundários porque não têm a função de preparar o corpo para o trabalho, assim como ocorre com os alimentos energéticos. O entendimento da população sobre alimentação saudável difere muito do entendimento técnico. Para eles, saudável é algo especial, não ligado à rotina, não é o básico, mas sim algum alimento que evoque diferenciação social, é uma comida de que se gosta e que não faz mal à saúde ${ }^{12}$.

O consumo de frutas é favorecido pela disponibilidade delas durante o trabalho nas plantações, mas esse consumo é uma reação à presença delas no momento e não é sequer lembrado quando rememoram os alimentos consumidos, porque, de fato, "as frutas pertencem muito mais à esfera do trabalho do que da "comida"12.

O trabalho em regime de meação não favorece o consumo de verduras porque o tempo despendido com o cultivo e preparação compete com o de trabalho na lavoura. Além disso, de acordo com informação prestada pelos entrevistados, os proprietários não incentivam o plantio porque isso aumenta o consumo de água e reduz o tempo de trabalho do meeiro na produção de frutas. Por outro lado, o consumo de FVL é favorecido por troca de produtos entre vizinhos.
Em relação aos professores, observou-se que a representação que eles têm da condição dos alunos da escola rural não corresponde aos resultados constatados na pesquisa. Para os professores, os alunos são muito carentes, "passam fome" e "vêm à escola para comer". A promoção da alimentação saudável é entendida pelos professores como "ensino de ciências" e "fornecimento de alimentos na merenda". Constatou-se a existência de uma opinião de que não era adequado incluir frutas na merenda porque são alimentos "fracos" e as crianças necessitam receber "comida". Paradoxalmente, a própria escola comercializava guloseimas para as crianças, as quais eram armazenadas e vendidas na diretoria da escola, com a finalidade de angariar recursos para atividades extracurriculares. Se por um lado consideravam as crianças mais pobres até do que realmente eram, por outro os educadores as induziam a gastar, dentro da própria escola, seus parcos recursos em alimentos supérfluos e não saudáveis ${ }^{13}$.

Os professores que trabalhavam nos dois períodos, geralmente compartilhavam da merenda, pois dispunham de apenas uma hora entre os dois períodos, que eles utilizavam para se deslocar de uma escola para outra e, em alguns casos, de um município para outro. A maioria deles residia em zona urbana não se identificando com a cultura local.

Os estudantes trabalhavam na terra, ajudando seus pais na produção de frutas, e tinham um significativo domínio das técnicas de produção, porém as entrevistas deixaram entrever que os professores não valorizavam esse conhecimento e subestimavam a capacidade dos alunos por considerá-los "muito pobres", fato agravado pela condição de não terem "emprego" formal. Tal conotação não era partilhada pela comunidade, que se considerava "remediada" e manifestava frequentemente orgulho pela capacidade de trabalhar a terra e produzir as frutas de forma autônoma. A representação que os professores tinham da condição dos alunos da escola rural constituía um obstáculo a um trabalho mais exigente com eles em sala de aula ${ }^{13}$. 
Face a este diagnóstico, estabeleceu-se como objetivo geral do programa, incentivar o consumo de alimentos produzidos na região, promovendo entre os atores sociais da escola uma reflexão sobre os limites e as possibilidades das escolas frente à problemática fome/pobreza/desnutrição. Os objetivos específicos foram: a) incentivar o consumo dos alimentos produzidos na comunidade; b) promover o conhecimento e a valorização do trabalho dos agricultores; c) apoiar o programa de alimentação escolar da Secretaria Municipal de Educação, enquanto atividade de educação, socialização e promoção da saúde.

O conhecimento da comunidade e da escola em termos de dados socioeconômicos, bem como de dados relativos ao consumo alimentar das famílias, contexto de vida e aspectos culturais da comunidade e da escola foram decisivos para nortear a concepção do conteúdo e das estratégias. Esse diagnóstico precedeu o programa cuja descrição e análise constituem objeto do presente artigo.

\section{MÉTODOS}

A escola onde foi realizado o trabalho situa-se na zona rural de um Município do Circuito das Frutas, Estado de São Paulo, Brasil. Nela trabalhavam, em 2006, 12 professores, duas merendeiras, uma coordenadora pedagógica, um assistente administrativo e o diretor. A escola contava com 155 alunos, distribuídos em pré-escola, Infantil II e ensino fundamental de $1^{\mathrm{a}}$ a $7^{\mathrm{a}}$ séries. Para o planejamento e execução do programa contou-se com a colaboração de quatro nutricionistas. A escola era pequena, considerada como a mais carente de recursos das escolas do Município. Foi escolhida justamente por refletir uma condição particularmente desafiadora para os pesquisadores em educação.

O projeto "Promoção da saúde, segurança alimentar e nutrição: a contribuição da educação nutricional" foi financiado pelo Conselho Nacional de Desenvolvimento Científico e Tecnológico (CNPQ) (Processo 402078/2005-5) e aprovado pelo Comitê de Ética em Pesquisa da Faculdade de Ciências Médicas da Universidade Estadual de Campinas, sob protocolo 242/2005 e todos os participantes assinaram termo de consentimento livre e esclarecido.

O método empregado no programa educativo, bem como as estratégias selecionadas e as tecnologias desenvolvidas a partir da pesquisa diagnóstica foram pautados sobre os conceitos de promoção da saúde, nutrição comunitária e educação nutricional problematizadora.

A promoção da saúde, conforme esta abordagem vem sendo construída ao longo das várias conferências sobre o tema, consiste no "processo de capacitação da comunidade para atuar na melhoria da qualidade de vida e saúde, incluindo uma maior participação no controle desse processo", tal como foi definida na Carta de Ottawa, documento final da primeira conferência ${ }^{15}$.

Por nutrição comunitária ${ }^{16,17}$ entende-se o processo de desenvolver intervenções integradas, concebidas a partir do diagnóstico da realidade social e cultural, dos usos e costumes, reconhecendo a variedade de circunstâncias e situações possíveis, condicionantes do padrão alimentar de uma população. As intervenções visam melhorar a qualidade da alimentação por meio do processo de capacitação dos sujeitos para a ação, tanto no que concerne à aquisição de conhecimento, como no compromisso com a transformação do status quo, o que vem sendo referido na literatura como empowerment ${ }^{18}$.

Finalmente, tomou-se como conceito de educação nutricional o de que esta consiste em:

Um conjunto de estratégias sistematizadas para impulsionar a cultura e a valorização da alimentação, concebidas no reconhecimento da necessidade de respeitar, mas também modificar crenças, valores, atitudes, representações, práticas e relações sociais que se estabelecem em torno da alimentação, visando o acesso econômico e social de todos os cidadãos a uma alimentação quantitativa e qualita- 
tivamente adequada, que atenda aos objetivos de promoção da saúde, prazer e convívio social ${ }^{19}$ (p.18).

A combinação de métodos quantitativos e qualitativos empregados na etapa diagnóstica possibilitou criar uma intervenção educativa problematizadora a partir de elementos do contexto, do ambiente e da vida cotidiana da população. 0 programa foi alicerçado nos condicionantes objetivos e subjetivos da alimentação, e não na ciência da nutrição em si, pressuposto que se coaduna com a abordagem problematizadora de Paulo Freire $^{20}$.

A intervenção foi denominada "Ensinando a amar a terra e o que a terra produz". Na sua concepção, procurou-se contextualizar o tema tratado no cotidiano de vida da comunidade, ressignificando a alimentação e o trabalho das famílias, promovendo a valorização do trabalho na agricultura focado na produção de frutas, e na ampliação da compreensão dos professores sobre a realidade de vida das famílias dos alunos.

Além dos subsídios fornecidos pelas pesquisas prévias, foi necessário realizar um estudo sobre a produção de frutas e conhecer o universo vocabular dos agricultores para trazê-lo para o trabalho na escola. O emprego de tais palavras aproxima os educadores da cultura local, porque são palavras que contém sentido existencial e, por isso, conteúdo emocional, que dizem respeito à experiência, ao trabalho e ao cotidiano. À guisa de exemplo citamos: limpar (o terreno), roçar, estercar, pulverizar, desbrotar, colher, encaixotar, entre vários outros ${ }^{20}$.

As atividades desenvolvidas com os alunos foram planejadas em conjunto com a coordenadora pedagógica e as professoras. Ficou estabelecido que se construiria uma maquete do bairro, medindo dois metros de comprimento por um metro de largura, com elementos produzidos pelos alunos, representativos do bairro (estradas, escola, entre outros), das moradias e plantações. A maquete do bairro foi escolhida porque representava o contexto de vida dos alunos, ou seja, por meio dela foi trazido para dentro da escola o território e o trabalho dessa comunidade.

\section{RES U LT A D OS}

A implementação do programa ocorreu no final do ano letivo, cerca de 15 dias antes do término das aulas, devido à demora na aceitação pelos professores da proposta das pesquisadoras. Entretanto, a coordenadora pedagógica mostrou-se favorável porque vislumbrou ganhos para a escola, na medida em que havia um grupo interessado e disponível para coordenar e auxiliar na realização de uma atividade inovadora. Seu apoio foi fator decisivo para a consecução da proposta, pois a partir dele pode-se apresentar e discutir com os professores os resultados das pesquisas, o que os sensibilizou. Uma das professoras, contrária à execução do programa, inicialmente argumentava que a atividade era desnecessária, porque já se havia ensinado o conteúdo de nutrição previsto no livro didático. Porém, quando ficou claro para todas que o conteúdo proposto era extraído do resultado das pesquisas e refletia questões do cotidiano de vida dos alunos, elas se motivaram e logo sugeriram que essa apresentação também fosse feita para os pais.

Fez-se uma adaptação do conteúdo para essa apresentação, compatibilizando-a com o nível de compreensão das famílias. Foram abordados apenas os resultados da pesquisa, pois não se teve por propósito ensinar algo a eles sobre alimentação, mas apenas compartilhar as informações adquiridas por meio da pesquisa, sobre o consumo de alimentos. Essas informações, por si só, desencadearam uma discussão a respeito do paradoxo de trabalhar na terra, como agricultor, produzir frutas, legumes e verduras e consumir pouco esses alimentos. Essa discussão não foi fechada com recomendações, mas deixou-se em aberto, para que a reflexão sobre o tema fosse levada para os familiares que não estavam presentes à reunião.

As atividades com os alunos foram implementadas em cinco etapas: a primeira, que serviu como elemento motivador, consistiu em contar para os estudantes de todas as séries uma história, criada por uma das alunas de pós-graduação, denominada "Chico-Bento Plantador de Figo", 
utilizando este personagem, que já era conhecido pelos estudantes, dos gibis. A história valorizou a origem da fruta, o trabalho da produção, pondo em evidência a atuação da mulher na lavoura, e finalmente foram mostrados os vários destinos da produção, procurando por em relevo o conhecimento que os alunos já traziam sobre o tema. A segunda etapa consistiu na realização de atividades em sala de aula relacionadas à atividade agrícola (palavras cruzadas, calendário agrícola, caça-palavras), todos eles preparados especialmente para o programa, a partir do estudo feito sobre a cultura das frutas. Na terceira etapa foram preparados, em sala de aula, os elementos da maquete, usando materiais como papel crepon, palitos, esponjas pintadas com tinta guache, caixas de fósforo e outros. Cada turma preparou um dos elementos: plantações de figo, goiaba, morango e uva, casas, poços, fossas, cercas, escola e outros. Na quarta etapa, realizada em um dia apenas, foi montada a maquete. Cada classe veio ao pátio coberto onde já estava preparada a base dela, contendo as estradas que cortam o bairro. Inicialmente foi estabelecido, com os alunos, um diálogo acerca do significado dos vários elementos no conjunto do trabalho e cada classe colocou o elemento que havia preparado. A quinta etapa consistiu em os alunos provarem o figo, gratuitamente fornecido por um dos produtores da região. As crianças degustaram com grande prazer a fruta e praticamente não houve recusas. Uma professora ficou constrangida porque nunca havia comido um figo, conquanto lecionasse para filhos de produtores dessa fruta em uma escola situada em meio às plantações. As cozinheiras da escola foram envolvidas nesta etapa final, o que as levou a reconhecer os alunos como co-participantes do trabalho na região de produção de frutas.

A maquete permaneceu exposta até o término das aulas, quando, por ocasião da festa de encerramento do ano letivo, os pais puderam apreciar o trabalho. Ao perceberem o seu fazer cotidiano como elemento central do trabalho escolar, sentiram-se orgulhosos e gratificados. Causou surpresa a muitas pessoas o fato do con- texto de vida e de trabalho ter sido refletido em programa de incentivo ao consumo de frutas, verduras e legumes.

Houve grande interesse dos alunos porque a maquete refletia o seu cotidiano e valorizava o trabalho e a história de suas famílias. O respeito por essa atividade e a possibilidade de expressarem saberes sobre as lavouras de fruta, socialmente construídos na prática comunitária, fortaleceu a autoestima dos alunos e de seus familiares. Ao comerem o figo, os alunos literalmente "in-corporaram" o produto do trabalho de suas famílias, produto esse que muitos nem sequer haviam provado e não consideravam que pudesse thes servir de alimento. As frutas produzidas eram consideradas por muitos apenas como um produto do trabalho ao qual eles mesmos não tinham direito, e a atividade possibilitou vivenciar este consumo como direito dos que a produzem.

Comer o figo foi um ato de apropriar-se de um direito - o direito ao fruto do próprio trabalho, que, neste caso, era a fruta. O alcance dessa experiência pode ser ainda aquilatado considerando-se que uma das professoras nunca havia provado um figo e manifestou até certo temor de experimentá-lo por ser desconhecido. Durante o planejamento esta professora foi a que mais ofereceu resistência, dizendo que já havia ensinado a pirâmide alimentar. Foi-lhe então explicado que o objetivo da ação educativa não era transmitir conhecimento técnico, mas possibilitar aos alunos uma experiência e reflexão crítica sobre suas práticas alimentares e sobre a importância do trabalho do agricultor que produz alimento para consumo.

A despeito da boa receptividade ao programa, que inclusive foi divulgado pela mídia local falada e escrita, quando, no ano seguinte, se quis retomar o contato, houve retraimento por parte das autoridades locais, que não apoiaram a continuidade do mesmo. Alguns representantes municipais foram convidados a assistir as defesas das dissertações de mestrado que compuseram o projeto como um todo, e, nas apresentações, vieram à luz fatos como a comercialização de guloseimas 
na escola e a falta de condições dos professores para fazer suas refeições em função do reduzido tempo entre o turno da manhã e o da tarde, realizado em outra escola e em outro município. O fato desagradou algumas autoridades locais.

\section{I S C U S S Ã O}

Uma limitação importante a ser apontada foi o fato de que o programa em pauta não estava previsto no calendário escolar, sendo essa uma das razões pelas quais houve resistência dos professores em incluí-lo na programação. A resistência foi dissipada quando os professores compreenderam que o programa proposto vinha de um diagnóstico amplo, composto por informações relativas às condições socioeconômicas, à cultura, ao consumo de alimentos, enfim àquilo que em linguagem pedagógica se convencionou chamar de uma "leitura do mundo", empregando uma expressão de Paulo Freire ${ }^{21}$. A intervenção focada no contexto de vida tornou a experiência atraente e significativa para alunos e professores participantes.

O desagrado causado pela discussão sobre as condições de trabalho dos professores é também um dado relevante do resultado, porque a saúde dos escolares não pode ser promovida em descompasso com a promoção da saúde dos professores. A atitude que o professor terá em relação à alimentação dos alunos será construída a partir de suas próprias práticas e condições de vida. Inclui-se aí o seu estresse diário, o esforço que é exigido para cuidar de si, de forma que não se pode excluir desse processo, o bem-estar docente ${ }^{22}$. A resistência das autoridades municipais para considerarem esses aspectos também constituiu um conflito de interesses em relação à proposta da equipe.

Embora os autores do presente artigo não tenham podido dar continuidade ao programa, pode-se afirmar que ele despertou interesse no município e, de algum modo, passou a fazer parte do repertório de experiências pedagógicas dos professores que dele participaram. Freire lembra que "se alcança a razão dos obstáculos na medida em que as ações são cerceadas"23, como aconteceu em relação à continuidade do programa. Ressalta-se, contudo, que fatos como esse constituem subsídios importantes às políticas de segurança alimentar e nutricional, pois é preciso conhecer os óbices que se encontra em campo, e o confronto de olhares para um problema constitui parte de uma educação que busca o diálogo ${ }^{20}$.

A proposta de promoção da alimentação saudável na escola conflita com interesses econômicos de empresas fornecedoras de alimentos para a merenda, mas também, como se observou neste estudo, com práticas de comercialização de alimentos existentes na própria escola ${ }^{13}$. Tudo isso se mantém em decorrência de um alto grau de ceticismo em relação ao poder da escola para alterar comportamentos alimentares (reforçados pela venda de produtos no interior da própria escola) e com a crença de que a função da merenda é apenas a de "atrair" o aluno para a escola. Acresce-se a isto o fato de que no local onde o programa foi desenvolvido, há efetivamente interesse de expulsar o agricultor do campo, para explorar a terra com expansão imobiliária, de forma que o objetivo de valorizar o trabalho do agricultor e incentivá-lo a fixar-se na terra conflita com interesses econômicos no campo imobiliário. Face a todos esses fatores, os programas de educação alimentar restritos a conteúdo técnico como nutrientes, funções de nutrientes, pirâmide de alimentos, culinária, são mais aceitos porque não exigem diagnóstico prévio e não geram conflito de interesses. A educação freireana não parte das categorias abstratas, das especializações, dos conhecimentos técnicos e científicos, mas das necessidades sentidas, relativas às condições concretas de vida, como trabalho, emprego, fome, moradia, analfabetismo. Se por um lado se enfrentou obstáculos como os que foram descritos, por outro foi possível distinguir, na reação das famílias, um alento de esperança em relação ao trabalho agrícola, e para Freire, a educação tem por função, reinstalar a esperança ${ }^{20}$. 
Historicamente, a alimentação nunca foi de fato valorizada dentro das Secretarias de Educação, principalmente porque apreende-se dela uma parcela ínfima, frente ao seu potencial mobilizador. Ao se estabelecer a relação da alimentação com o trabalho das famílias dos alunos na produção de alimentos, esse tema ganhou um novo significado, sendo este, por sua vez, gerador de novos sentidos para o trabalho docente. É importante esclarecer que neste estudo não se teve a pretensão de enveredar pela discussão sociológica que se trava entre o que os especialistas na área de pedagogia concebem como educação no campo ou educação rura|24, 25. O propósito é tão somente analisar a experiência de educação alimentar e nutricional realizada fora do espaço urbano, com produtores de frutas, ressaltando que, no seu decorrer, foi possível perceber que questões problemáticas apontadas pelos especialistas em educação no campo e educação rural também estiveram presente nesse trabalho: 1) conteúdo escolar distante da realidade de vida e de trabalho dos alunos filhos de agricultores; 2) crença entre os professores de que a evolução positiva do aluno em termos educacionais servirá para afastá-lo do campo e do trabaIho agrícola, uma vez que se acredita que é no espaço urbano que se vive o progresso. Ao longo do percurso foi necessário enfatizar que não se considerava a população de agricultores ignorante, mas que se acreditava que aquele espaço de trabalho, estudo e moradia poderia ser também um local de resgate da identidade e da cultura dos agricultores, numa perspectiva de desenvolvimento humano.

Encontra-se na literatura especializada, relatos de experiências de programas de educação alimentar e nutricional na escola. Busca-se ações mais abrangentes ${ }^{26}$, algumas focadas no consumo de alimentos ${ }^{27}$, outras no ensino de nutrição ${ }^{28} \mathrm{e}$ outras ainda que avançam mais no desenvolvimento de novas metodologias, como o de Castro et al.29, fazendo uma aproximação da promoção da saúde com a culinária. O que fundamentalmente difere em nossa experiência é o estímulo ao consumo pela valorização da origem do produto, ao invés de pelo conteúdo em nutrientes, ou seja, a ressignificação da fruta enquanto produto do trabalho das famílias dos fruticultores.

O reconhecimento e a assunção da identidade cultural ${ }^{30}$, neste caso identidade de agricultor, é um aspecto que o programa possibilitou trabalhar. Algumas professoras expressaram um sentimento que até então não se Ihes havia aflorado, de desconforto pelo fato de conhecerem muito pouco sobre a região onde moravam os alunos. Pensou-se em levá-las a uma excursão pelo bairro, na qual elas teriam possibilidade de conhecer o território, inclusive por intermédio de seus próprios alunos que mostrariam as diversas culturas e explicariam os procedimentos de cultivo que eles conheciam muito bem. Não houve tempo disponível para realizar essa atividade, mas ela está citada aqui como uma necessidade detectada e uma possibilidade de atividade extraclasse. A inversão de papéis seria uma estratégia reveladora do conhecimento das famílias sobre a cultura das frutas, o que thes reforçaria a autoestima e aos professores traria subsídios à contextualização do ensino.

O resgate do valor humano e consequentemente da autoestima é uma condição para o protagonismo social, que viabiliza ações de natureza política. Mais do que ensinar a comer frutas, é preciso valorizar o trabalho do agricultor para que ele deseje se fixar à terra, e não tenha como meta de sua vida abandonar o campo, ideário que era compartilhado inclusive por alguns professores. Esse é um dos significados de empowerment. Nessa linha de pensamento é interessante refletir sobre as palavras de Novara ${ }^{31}$ :

Cada pessoa, cada comunidade, por mais carente que seja, representa uma riqueza e demonstra um grande valor. Para ajudar a desenvolver os próprios talentos e a mover a responsabilidade pessoal, é necessário valorizar e reforçar aquilo que as pessoas já construíram, a própria história, as relações existentes, isto é, reafirmar aquele tecido social e aquele conjunto de 
experiências que constitui o patrimônio de vida. É um ponto operativo fundamental que nasce de uma abordagem positiva da realidade e que ajuda a pessoa a entender o seu próprio valor, a sua dignidade e, desse modo, a desenvolver uma responsabilidade (p.115).

De maneira análoga, Cândido ${ }^{14}$ disse a respeito dos meeiros com os quais trabalhou no interior paulista: "Eram todos analfabetos, sendo alguns admiráveis pela acuidade de sua inteligência" (p.18).

A pesquisa prévia revelou-se de grande valia porque possibilitou desenvolver uma compreensão a respeito da cultura e dos valores norteadores da vida dos sujeitos e criar tecnologias de intervenção inéditas a partir da observação e da crítica. Conforme diz Freire, ensinar exige pesquisa, pois constatando os fatos torna-se possível ensinar intervindo e provocando mudanças na realidade, o que é mais complexo, mas também mais instigante para a geração de novos saberes ${ }^{30}$. Esta metodologia pressupõe que o ponto de partida da educação alimentar e nutricional não deva ser a ciência da nutrição em si, mas as práticas, os valores, as representações, enfim, a realidade de vida dos educandos. Esta proposta difere fundamentalmente da intenção de apenas estimular o consumo de frutas, verduras e legumes porque são alimentos saudáveis, porque permite desenvolver tecnologias específicas para atuar sobre a cultura e os valores. É importante ressaltar que o termo tecnologia refere-se ao desenvolvimento, organização e utilização de recursos educacionais a partir de resultados de pesquisas, pois ocasionalmente ele pode ser empregado para referir emprego de equipamentos. A tecnologia educacional pode até prescindir de qualquer equipamento, pois, antes de tudo, a educação é uma interação humana.

É possível afirmar que a intervenção educativa causou um impacto positivo nos professores envolvidos, que perceberam não só o potencial do tema alimentação para estabelecer interconexões entre as várias áreas do conhecimento, aproveitando oportunidades que surgem no coti- diano escolar, mas o valor do trabalho que existia ao redor da escola.

Outro aspecto importante foi o oferecimento da fruta aos alunos e professores durante a montagem da maquete, o que constituiu uma ação de educação do paladar, ou seja, da dimensão sensível do ser humano. Enquanto conceitos e informações são objetos do conhecimento intelectivo, sensações - visão e aroma da fruta, sensação tátil que ela provoca, sabor, ruído que se ouve ao mastigá-la, constituem o objeto do conhecimento sensível, tão necessário de ser estimulado face à degradação sensória ${ }^{32}$ que se vem observando, sobretudo na alimentação dos jovens, decorrente do consumo de produtos de qualidade duvidosa que existem no mercado.

Programas educativos que são pautados na realidade proporcionam oportunidades para identificar barreiras relativas à qualidade de vida, à emancipação e ao controle sobre a vida e o trabalho, porém encontram resistência ante aos poderes constituídos. As desigualdades sociais poderiam ser reduzidas com implementação de programas de alfabetização e ensino supletivo na região. Em médio prazo, a escolarização poderia contribuir para que os contratos de meação fossem estabelecidos por meio de instrumentos legais entre proprietários de terra e meeiros. Este aspecto exige medidas intersetoriais que seriam do âmbito dos Conselhos Municipais.

Ao se iniciar esse programa, no ano de 2005, quase não havia na literatura científica brasileira, relatos de experiências sobre promoção da alimentação saudável na escola. A Portaria Interministerial 1010/2006, que instituiu as diretrizes para a Promoção da Alimentação Saudável nas Escolas de educação infantil, fundamental e nível médio das redes públicas e privadas, em âmbito nacional foi posterior à formulação inicial da pesquisa e, sem dúvida, vem respaldar iniciativas como a deste trabalho. Posteriormente, a Lei Federal 11.947 de 16 de junho de 2009, constituiu mais um importante passo nesse sentido, pois estabelece, entre outros pontos, a obrigatoriedade da educação alimentar e nutricional na escola. 


\section{ONCLUSÃ O}

Os resultados demonstraram a possibilidade de realizar um programa de incentivo ao consumo de alimentos produzidos na região, no qual o tema alimentação teve como ponto de partida não a ciência da nutrição em si, mas a relação homem/ambiente, mediada pelo trabalho, as práticas de consumo, valores e representações. Esses resultados possibilitaram a criação de tecnologia educacional específica para um programa de educação alimentar e nutricional nessa escola. Houve grande interesse dos alunos pelas atividades realizadas porque elas refletiam o seu próprio cotidiano e valorizavam o trabalho, a história, a identidade cultural e a autoestima das famílias de fruticultores. A fruta foi ressignificada enquanto direito do próprio agricultor que a produz.

Nos professores, a experiência efetivamente provocou reflexão sobre os limites e possibilidades da escola frente à problemática da fome, pobreza/desnutrição, na medida em que eles tiveram acesso aos resultados da pesquisa e também por serem surpreendidos com o domínio de conhecimentos dos seus alunos sobre as práticas da fruticultura. Em decorrência do fato de não terem conhecimento suficientemente amplo das questões de alimentação para poderem incorporar esse tema ao ensino e, por isso, oferecem resistência a ele, a assessoria de especialistas é necessária para sensibilizá-los e apoiá-los no ensino dos temas transversais, particularmente daqueles relacionados à alimentação. Além disso, é imprescindível que as atividades sejam previstas no cronograma escolar e ocorram integradas às demais atividades que compõem o currículo.

O objetivo de incentivar o consumo dos alimentos produzidos na região foi trabalhado atrelado à valorização do trabalho e do conhecimento dos agricultores, e esses objetivos foram plenamente atingidos.

As atividades realizadas apoiaram o programa de alimentação escolar, na medida em que os seus objetivos estiveram presentes nas discussões com os professores, quando se procurou dar relevo aos aspectos de educação alimentar e nutricional, socialização e promoção da saúde inerentes ao programa, e também pelo envolvimento das cozinheiras da escola.

A análise do programa realizado à luz do pensamento freireano possibilitou compreender o alcance e a natureza dos obstáculos encontrados. Os conflitos de interesses identificados também constituem subsídios importantes às políticas públicas de segurança alimentar e nutricional, pois refletem obstáculos que se interpõem à sua implementação.

A educação alimentar e nutricional contextualizada não é uma ação técnica estrita. $\mathrm{O}$ desenvolvimento do trabalho faz emergir confronto de olhares, conflitos de interesses, ideias divergentes, especialmente quando se justapõem às visões de diferentes profissionais, mas o entendimento precisa ser buscado, pois o diálogo entre iguais é apenas uma ressonância do próprio pensamento. Somente o diálogo entre diferentes faz nascer o novo.

\section{A GRADECIMENTOS}

Pela colaboração de Ana Paula Fioreti, Erica Blascovi de Carvalho, Miriam Corrêa de Carvalho (in memorian) e Tais Polido Bais na implementação do programa educativo.

\section{REFERÊ NCIAS}

1. Jaime PC, Monteiro CA. Fruit and vegetable intake by Brazilian adults. Cad Saúde Pública. 2005; 21(Supl):S19-S24. doi: 10.1590/S0102-311X2005 000700003.

2. Levy-Costa RB, Sichieri R, Pontes NS, Monteiro CA. Disponibilidade domiciliar de alimentos no Brasil: distribuição e evolução (1974-2003). Rev Saúde Pública. 2005; 39(4):530-40. doi: 10.1590/S0034-8 9102005000400003.

3. Brasil. Ministério da Saúde. Portaria n. 710 de 1999. Política nacional de alimentação e nutrição. $2^{\mathrm{a}}$ ed. Brasília; 2003.

4. Bizzo MLG, Leder L. Educação nutricional nos parâmetros curriculares nacionais para o ensino fundamental. Rev Nutr. 2005; 18(5):661-7. doi: 10.15 90/S1415-52732005000500009. 
5. Burlandy L. Segurança alimentar e nutricional: intersetorialidade e as ações de nutrição. Saúde Rev. 2004; 6(13):9-15.

6. Garcia WG. Inclusão do tema alimentação/nutrição nos cursos de pedagogia. Anais do Simpósio Escola, Nutrição e Saúde: desafios contemporâneos. São Paulo: Instituto de Estados Avançados da Universidade de São Paulo; 2005.

7. Morin E. Os sete saberes necessários à educação do futuro. $3^{\text {a }}$ ed. São Paulo: Cortez; 2001.

8. Brasil. Lei 11.346, de 15 de setembro de 2006. Cria o Sistema Nacional de Segurança Alimentar e Nutricional - ISAN. Diário Oficial da União. 2006; 18 set.

9. Poulain JP, Proença RPC. Reflexões metodológicas para o estudo das práticas alimentares. Rev Nutr. 2003; 16(4):365-86. doi: 10.1590/\$1415-273200 3000400001 .

10. Minayo MCS. Mudança: conceito-chave para intervenções sociais e para avaliação de programas. In: Minayo MCS, Assis SG, Souza ER, organizadores. Avaliação por triangulação de métodos. Rio de Janeiro: Fiocruz; 2005. p.53-70.

11. Boog MCF, Fonseca MCP, Alves HJ, Voorpostel CR. Agricultores consomem frutas verduras e legumes? Bases para ações educativas. Segurança Alimentar e Nutricional. 2008; 15(2):85-97.

12. Alves HJA, Boog MCF. Representações sobre o consumo de frutas, verduras e legumes entre fruticultores de zona rural. Rev Nutr. 2008; 21(6):705-15. doi: 10.1590/S1415-52732008000600009.

13. Voorpostel, CR. Percepções de professores e funcionários de escola rural sobre a alimentação [dissertação]. Campinas: Universidade Estadual de Campinas; 2007.

14. Cândido A. Os parceiros do Rio Bonito: estudo sobre o caipira paulista e a transformação dos seus meios de vida. 9a ed. São Paulo: Duas Cidades; 2001.

15. Buss PM. Uma introdução ao conceito de promoção da saúde. In: Czeresnia D, Freitas CM. Promoção da saúde: conceitos, reflexões, tendências. Rio de Janeiro: Fiocruz; 2003. p.15-38.

16. Aranceta J. Nutrición comunitária. ALAN. 2004; 54 (Supl 1):9-13.

17. Serra-Majem L. Las mejores práctica en nutrición comunitaria: retos y compromisos. ALAN. 2004; 54(Supl 1):40-3.

18. Carvalho SR. Os múltiplos sentidos da categoria "empowerment" no projeto de promoção à saúde. Cad Saúde Pública. 2004; 20(4):1088-95. doi: 10.1590/S0102-311X2004000400024.

19. Boog MCF. A contribuição da educação nutricional à construção da segurança alimentar. Saúde Rev. 2004; 6(13):17-23.
20. Freire P. Educação como prática da liberdade. $22^{a}$ ed. São Paulo: Paz e Terra; 1994.

21. Gadotti M. Um legado de esperança. São Paulo: Cortez; 2001.

22. Brasil. Ministério da Saúde. A promoção da saúde no contexto escolar. Rev Saúde Pública. 2002; 36(4):533-5. doi: 10.1590/S0034-891020020004 00022.

23. Freire P. Educação e mudança. $10^{\mathrm{a}}$ ed. Rio de Janeiro: Paz e Terra; 1983.

24. Souza MA. Educação do campo: políticas, práticas pedagógicas e produção científica. Educ Soc. 2008; 29(105):1089-111. doi: 10.1590/50101-73302008 000400008.

25. Damasceno MN, Beserra B. Estudos sobre educação rural no Brasil: estado da arte e perspectivas. Educ Pesqui. 2004; 30(1):73-89. doi: 10.1590/\$1517-9 7022004000100005.

26. Pérez RC, Aranceta J, Brug H, Wind M, Hildonen C, Klepp KP. Estratégias educativas para la promoción del consumo de frutas y verduras en el médio escolar: proyecto pro children. ALAN. 2004; 54(supl 1):14-19.

27. Olivares S, Morón C, Kain J, Zacarias I, Andrade M, Lera L, et al. Propuesta metodológica para incorporar la educación em la enseñanza básica. La experiência de Chile. ALAN. 2004; 54(supl 1): 33-39.

28. Gaglianone CP, Taddei JAAC, Colugnati FAB, Magalhães CG, Davanço GM, Macedo L, et al. Nutrition education in public elementary schools of São Paulo, Brazil: the reducing risks of illness and death in adulthood project. Rev Nutr. 2006; 19 (3):309-20. doi: 10.1590/\$1415-52732006000 300002.

29. Castro INR, Souza TSNS, Maldonado LA, Caniné ES, Rotenberg S, Gugelmin SA. A culinária na promoção da alimentação saudável: delineamento e experimentação de método educativo dirigido a adolescentes e a profissionais das redes de saúde e educação. Rev Nutr. 2007; 20(6):571-88. doi: 10.1590/S1415-52732007000600001.

30. Freire P. Pedagogia da autonomia: saberes necessários à prática educativa. $7^{a}$ ed. São Paulo: Paz e Terra; 1998.

31. Novara E. Promover os talentos para reduzir a pobreza. Est Avan. 2003; 17(48):7-20. doi: 10.1590/S0 103-40142003000200009.

32. Duarte Jr JF. O sentido dos sentidos: a educação (do) sensível. $3^{\text {a }}$ ed. Curitiba: Criar; 2001.

Recebido em: 27/11/2009

Versão final reapresentada em: 3/5/2010

Aprovado em: 5/7/2010 
